\title{
Predicting risks and benefits of treatment with aspirin in the acute stage of ischaemic stroke: an analysis of 3 large randomised controlled trials
}

\author{
Douglas Thompson ${ }^{1 *}$, Gordon Murray ${ }^{1}$, William Whiteley ${ }^{1,2}$ \\ From 2nd Clinical Trials Methodology Conference: Methodology Matters \\ Edinburgh, UK. 18-19 November 2013
}

\section{Background}

Aspirin reduces the absolute risk of death or dependence following an acute ischaemic stroke. An associated increase in risk of haemorrhage may cause considerable harm. We hypothesised that patients at a high predicted risk of further thrombosis or a low risk of haemorrhage would experience greater absolute benefit from aspirin. In addition we explored the assumption that absolute benefit increases with baseline risk.

\section{Methods}

We applied formal prediction methods to the three largest randomised trials of aspirin in patients with acute ischaemic stroke. We developed new prediction models for early events (14 day thrombosis and haemorrhage) and for long term functional outcome (six month death or dependence) and internally evaluated their performance. We calculated the absolute risk reduction of death or dependence with aspirin within quarters of predicted patient risk from early events across trials and pooled the results using random effects meta-analysis.

\section{Results}

Simple prediction models discriminated early events poorly (AUROCC 0.56 and 0.60 ) but were moderate at discriminating long term death or dependence (AUROCC 0.77). There was no evidence of greater benefit or of harm from aspirin across the sixteen defined subgroups of predicted risk nor was there any evidence that absolute benefit increased linearly with baseline risk. The best estimate of the effect of aspirin was the overall absolute risk

${ }^{1}$ Edinburgh MRC Hub for Trials Methodology Research, University of Edinburgh, Edinburgh, UK

Full list of author information is available at the end of the article reduction of death or dependence of $1 \%$ (95\% CI: $0 \%$ to $2 \%$ ) in all risk groups.

\section{Conclusions}

We found no evidence to support targeting aspirin to acute ischaemic stroke patients with a high predicted risk of thrombosis or a low predicted risk of haemorrhage. The modest absolute benefit of aspirin was similar across predicted patient risk of death or dependence.

\section{Authors' details}

${ }^{1}$ Edinburgh MRC Hub for Trials Methodology Research, University of Edinburgh, Edinburgh, UK. ²Division of Clinical Neurosciences, University of Edinburgh, Bramwell Dott Building, Western General Hospital, Edinburgh, UK.

Published: 29 November 2013

doi:10.1186/1745-6215-14-S1-P117

Cite this article as: Thompson et al.: Predicting risks and benefits of treatment with aspirin in the acute stage of ischaemic stroke: an analysis of 3 large randomised controlled trials. Trials 2013 14(Suppl 1): P117.

Submit your next manuscript to BioMed Central and take full advantage of:

- Convenient online submission

- Thorough peer review

- No space constraints or color figure charges

- Immediate publication on acceptance

- Inclusion in PubMed, CAS, Scopus and Google Scholar

- Research which is freely available for redistribution

\section{Biomed Central}

